\title{
Unit-Wise Comparative Survey of Job Satisfaction and Related Factors
}

\author{
Suresh Kumar \\ Department of commerce, Govt. Degree College Bhoranj (Tarkwari), Hamirpur, (Himachal Pradesh), India \\ suresh.commerce@gmail.com
}

\begin{abstract}
This paper is an attempt to compare and contrast unit-wise job satisfaction levels and the commitment to stay at job was also determined .A sample of 360 employees drawn from the four different units located in Himachal and Punjab states. The Bhakra-Beas Management Board was undertaken as universe for the present study. The study was conducted during 2008 to 2010.The study found that the employees of different units does have significant difference on job satisfaction according to their units location and the work environment prevailing in the organization .The study further found that a few respondents responded to leave the organization in normal conditions. The fact confirms that the more satisfied employees will definitely supports the fact that they will stay until they retire from this job. The study recommends that a highly satisfied employee do have the opinion of above average performance or outstanding performance at job. Finally, the units found a significant place in the determination of attitude towards overall and dimension specific job satisfaction.
\end{abstract}

\section{Keywords: Satisfaction, Bhakra Beas Management Board (BBMB), commitment, compare, contrast}

\section{Introduction}

Job satisfaction constitutes the inner contentment that a job holder gets by performing the job well. It is an amount of pleasure associated with a job. It influences the behavior, attendance and length of service. Job satisfaction reflects the overall attitude of workers towards the work, co-workers, the organization, the culture, the environment and the social group at large. It can be viewed as the result of various attitudes that the worker holds towards his job, towards other related factors and towards life in general. The happiness or pleasure that an employee gets by using this knowledge and skill effectively, result in job satisfaction. It is the psychological satisfaction a person gets by using his strengths and talents effectively. Job satisfaction reflects the attitude which results from a balancing and summation of the many likes or dislikes and experiences in connection with a job. The mixture of feelings, attitudes and sentiments that contribute to a general feeling of satisfaction gives rise to job satisfaction. The growth of an organization depends upon the efficiency of its employees. The efficiency of the workers depends not only on how they work, but also on optimal social and physical conditions, in which they work. If they are not satisfied with their job or working conditions, the organization will not be able to achieve its objectives. Increasing job satisfaction is important for its humanitarian value and for its financial benefits in order for an organization to be successful. Therefore, they must continuously ensure the satisfaction of their employees. Many experts have tried to come up with an explanation for why people feel the way they do with regard to their job. Locke (1969) developed the idea known as Discrepancy Theory. The theory suggests that a person job satisfaction comes from what they feel is important rather than the fulfillment or un-fulfillment of their needs. Employees give the necessary feedback in order for employers to know if people are satisfied with their jobs. If a person is rewarded for doing the work, she/he may find the job more satisfying.

The present research paper attempts to achieve the following objective:

- To assess the unit -wise Job Satisfaction, commitment to stay with job and the job performance opinion of employees.

- To compare and contrast unit-wise Job Satisfaction levels and other related factors under study.

\section{Literature Review}

Maslow (1954) in his study of the hierarchy of human needs provided the basic foundation for many subsequent studies on job satisfaction. Job-satisfaction has been primarily based upon the gratification of needs: the stronger the needs, the more closely does job satisfaction depend on its fulfillment. Locke (1970) defined job satisfaction as a pleasurable or positive emotional state resulting from the appraisal of one's Job or Job experience. Job Satisfaction is a nebulous concept. It is axiomatic to state that people 
differ in regard to the extent to which they are satisfied with their job. Sathyadas (1979) concluded a comparative study of job satisfaction and temperament of teachers and clerks. The aims of the study were to find out the significance of difference between satisfied and dissatisfied teachers and between satisfied and dissatisfied clerks separately for neuroticism and extraversion. Dhillon (1989) investigated the relationship between perceived occupational stress and job satisfaction among 176 male officers of police organization in Delhi. Chaudhry (1989) studied occupational level and job satisfaction in a comparative study of public and private sector organization. The study was carried out with the two fold objectives to study and compare the extent of the job satisfaction among the employees of private and public sector and to compare the extent of job satisfaction within the hierarchical status. Mohammad (2000) conducted a study on job satisfaction among private and public sector bank employees. The study revealed that public bank employees were in a better position in terms of job satisfaction than the private sector.

The literature reviewed above provides a piecemeal account of research gap that there are a number of studies which accounts the job satisfaction of employees under private and public enterprises etc., but none of the study in India and outside has undertaken to assess the organization unit/project/office or site -wise job satisfaction where the working condition may be different. The present study is taken into account the four units/projects site of Bhakra-Beas Management Board, which is a public enterprise in India.

\section{Hypothesis}

H1: There is insignificant means difference on units Job Satisfaction score.

H2: Employees of different units would not have any significant bearing on Job Satisfaction, commitment to stay with job and the job performance.

\section{Research Methodology}

For the present research work qualitative approach is undertaken by the researcher. The selection of respondents were ultimately made on convenient - cum judgment method of non-probability sampling and the sample selection is shown in Table No.1 and the Unit-wise respondents picture has been presented in Table No.2.

Table 1: Sample Selection from Existing Population of BBMB

\begin{tabular}{lccc}
\hline Employees Categories & Sanctioned Strength & Existing Strength & Sample (5\%) \\
\hline A (officers) & 269 & 219 & $30^{*}$ \\
B (officers) & 409 & 290 & $30^{*}$ \\
C (Non-officers & 8183 & 6127 & 300 \\
D (Non-Officers) & 6175 & 4910 & Nil $^{* *}$ \\
Grand Total & 15036 & 11546 & 360 \\
\hline
\end{tabular}

*Sample Selection based on 5\% from each category (subject to a minimum of 30 employees of each category).

**'D' category employees were excluded from population on the basis of pilot survey and non-response behavior of this category

Table 2: Unit-Wise Respondents Distribution in BBMB

\begin{tabular}{clccc}
\hline S/N & \multicolumn{1}{c}{ Units/Projects } & Officers & Non-Officers & Total \\
\hline 1. & Bhakra Nangal & $25(41.60)$ & $125(41.66)$ & $150(41.69)$ \\
2. & Talwara (Beas Dam) & $15(25)$ & $70(23.33)$ & $85(23.61)$ \\
3. & Sundarnagar (BSL) & $10(16.66)$ & $65(21.66)$ & $75(20.83)$ \\
4. & Chandigarh Secretariat & $10(16.67)$ & $40(13.33)$ & $50(13.88)$ \\
& Total & $60(100)$ & $300(100)$ & $360(100)$ \\
\hline
\end{tabular}

* Figures in parenthesis show percentages to total

To accomplish the objectives of the present study utilized both primary and secondary data of Bhakra Beas Management Board. The primary data was collected by administrating the questionnaire. Bearing the important dimensions of job satisfaction, a number of variables related to job satisfaction inventory were collected from a number of sources i.e. present and former employers of Bhakra Beas Management Board and other organizations. The expert opinion in this field of this particular research was also 
attempted. The item pool thus refined was presented to the 30 experienced employees who were requested to add other statements that might be relevant to the subject to point out redundant statements to mark ambiguous and double barred "items" if any and to give suggestion for refining the items in the above pool. The suggestions were incorporated and 30 facets were selected and were included in the preliminary form. At a very early stage in the pilot study it becomes evident that certain items were either ambiguous, unclear or the respondents did not understand them properly. The discriminating potential and suggested changes by the respondents were also included in the final form. The flat and ambiguous statements were dropped. Since the statements were qualitative they were quantified on five point scale using likert type technique.

The questionnaire was divided into two sections; Section-1 was of personal data sheet comprising 16 socio-economic variables and section-2 of job satisfaction inventory (JSI). After the pilot survey a 21 facet job satisfaction inventory was employed with grouping of four job satisfaction dimensions as organizational factor dimension (6 facet), work-environment factor dimensions (6 factor) work itself factor dimension (4) and personal factor dimensions ( 5 factor) for items see appendices. Initially the permission of board administration was sought and four hundred questionnaires were distributed personally among respondents. The fully responded questionnaires were utilized for further processing. The instructions were written in the opening of various sections and sub sections of the questionnaire.

The Content item and construct validity of job satisfaction facets were established. The construct validity of inventory was found very high which ranges from 0.82 to 0.84 . The construct validity supports the items to total correlation validity. Reliability of the instrument was justified firstly through the calculation of cronbach's alpha $\alpha$ coefficient (cronbach's the observed coefficient value of job satisfaction scale $0.9110)$ has been observed above the Nunnally (1994) Criterion (0.70) hence could be classified as acceptable reliable instrument. The test-retest (one month interval between the two administration) measure of reliability coefficient for job satisfaction scale were found acceptable reliable $(>0.80)$. he responses on the job satisfaction inventory were assigned on a five point likert (1967) scale containing categories of highly satisfied (5) moderating satisfied (4) neither satisfied nor dissatisfied (3) Dissatisfied (2) Highly dissatisfied (1) figures in parenthesis denoting their weightage. In this manner scores on job satisfaction inventory for low medium and higher level has been determined. The summated score may range between 21 to 105. Keeping in view the objectives and the nature of data required under study the questionnaire method for data collection and the help of Mathematical, Tabular and the Statistical methods were used. Statistical analysis was performed through the SPSS -17 packages.

\section{Analysis and Discussion}

Unit-Wise analysis of job satisfaction and related factors: There is evidence that increased satisfaction is related to enhanced productivity (Herzberg, Mouster and Snyderman, 1959, Spector, 1997). The progressive organizations therefore, regularly measure the satisfaction index to take corrective measures. The responses on the Job Satisfaction inventory were assigned on a five point likert scale containing categories of 'highly satisfied' (5), 'moderately satisfied' (4), 'Neither satisfied nor dissatisfied' (3), 'Dissatisfied' (2) and 'Highly dissatisfied' (1), figures in parenthesis denoting their weightage. In this manner scores on Job Satisfaction inventory for low, medium and higher levels were summated. The score may range between 21 to 105 . The total sample of 360 employees was selected from four different units of Bhakra Beas Management Board viz., Bhakra Nangal project, Talwara (Beas Project), Sundernagar (BSL Project) and Chandigarh Secretariat. It is evident that overall mean job satisfaction score of the employees is 81.95. Which is much higher than the standard mean score (63). The mean values clears that Talwara and Sundernagar employees have shown a higher Job Satisfaction mean score than the overall mean score observed (81.95). The highest mean score among the units was observed in Talwara unit, which had scored 86.49. The lowest mean score of the job satisfaction was Chandigarh secretariat i.e., 77.32. The observed mean scores indicate a big difference among the four units of BBMB.

Table 3: Unit-Wise Analysis of the Job Satisfaction: An Analysis

\begin{tabular}{clccc}
\hline S. No. & \multicolumn{1}{c}{ BBMB Units } & $\mathbf{N}$ & Mean $(\bar{X})$ & S.D $(\boldsymbol{\sigma})$ \\
\hline 1. & Bhakra-Nangal & $150(41.66)$ & 79.21 & 10.36 \\
2. & Talwara (Beas Dam) & $85(23.61)$ & 86.49 & 11.30 \\
3. & Sundernagar (BSL) & $75(20.83)$ & 85.40 & 9.97 \\
4. & Chandigarh (Secretariat) & $50(13.88)$ & 77.32 & 10.46 \\
& Total & $360(100)$ & 81.95 & 11.11 \\
\hline
\end{tabular}

Note: Figures in parenthesis shows percentages to total. 
Table 4: Unit-Wise Variance Analysis on Job Satisfaction

\begin{tabular}{cccccc}
\hline Groups & Ss & df & MS & 'F' Value & 'P' Value \\
\hline Between Groups & 4848.56 & 3 & 161.19 & & \\
Within Groups & 39470.72 & 356 & 110.87 & & $<0.01$ \\
\hline
\end{tabular}

It is derived from the table that the obtained ' $F$ ' ratio 14.58 was significant at 0.01 level of significance. This shows that job satisfaction of employees of different units does have significant difference according to their unit location and the work-environment prevailing in the organization. It can be further viewed that the observed mean difference among units was not due to by chance but the difference found statistically significant. The hypothesis (Ho) in this regard may be rejected that there would not have been any significant bearing on the Job Satisfaction score. Therefore, the management must have to think upon the issue of significance of difference in job satisfaction of different units.

Unit's employees in BBMB: The level of satisfaction has been measured on five point likert scale ranging from highly satisfied to not satisfy with single item. Table reveals that out of 360 employees, interviewed for the study, only four employees, i.e. 1.1 percent were found not satisfied with their jobs. 6.1 per cent of employees were found slightly satisfied with their job, while 7.8 percent respondents feel satisfied with their job. It is important to interpret that a majority employees feels highly satisfied with their job $(43.3$ and 41.1 percent). Thus, the satisfied employees out-number as compared to the employees who were not satisfied. The numbers of the employees on the higher side were found high as compared to other end. Thus, the few workers were found dissatisfied with their Job in the organization. When the sample was analyzed unit-wise, it was observed that the number of highly satisfied employees revealed maximum in Sundarnagar unit with 54.7 percent. The number of dis-satisfied employees is maximum in Chandigarh unit of BBMB. But in Sundernagar unit no employee has shown dissatisfaction towards Job.

Table 5: Unit Wise Analysis of Job Satisfaction Ratings

\begin{tabular}{clcccccc}
\hline S/N & BBMB Units & $\begin{array}{c}\text { Not } \\
\text { Satisfied }\end{array}$ & $\begin{array}{c}\text { Slightly } \\
\text { Satisfied }\end{array}$ & Satisfied & $\begin{array}{c}\text { Quite } \\
\text { Satisfied }\end{array}$ & $\begin{array}{c}\text { Highly } \\
\text { Satisfied }\end{array}$ & Total \\
\hline $\mathbf{1}$ & Bhakra Nangal & 2 & 12 & 14 & 73 & 49 & 150 \\
& & $(1.33)$ & $(8)$ & $(9.33)$ & $(48.66)$ & $(32.7)$ & $(100)$ \\
$\mathbf{2}$ & Talwara & 0 & 3 & 7 & 31 & 44 & 85 \\
& (Beas-Dam) & $(0)$ & $(3.5)$ & $(8.2)$ & $(36.5)$ & $(51.8)$ & $(100)$ \\
\multirow{3}{*}{$\mathbf{3}$} & sundernagar & 0 & 1 & 6 & 27 & 41 & 75 \\
& (BSL) & $(00$ & $(1.5)$ & $(8.60)$ & $(36)$ & $(54.7)$ & $(100)$ \\
$\mathbf{4}$ & Chandigarh & 2 & 8 & 1 & 25 & 14 & 50 \\
& (Secreteriate) & $(4)$ & $(16)$ & $(2)$ & $(50)$ & $(28)$ & $(100)$ \\
& & 4 & 24 & 28 & 156 & 148 & 360 \\
& Total & $(1.1)$ & $(6.7)$ & $(7.8)$ & $(43.3)$ & $(41.1)$ & $(100)$ \\
\hline
\end{tabular}

Note: Figures in parenthesis shows percentages to total.

Analysis of Employee's Commitment to Stay with Job: Table 6 shows cross tabulation of units with their stay to the present job. The respondents of the BBMB were asked to rate the statement like, what would be their plans to stay with this job in future. The four different answers were found like (i) I want to stay until I retire (ii) I will leave only if an exceptional opportunities turns up (iii) I will leave, if something better turns up. (iv) I intend to leave, as soon as possible, by asking the above statement, from the respondents. It has been determined that how many employees want to leave the organization or its vice-versa. Therefore, an attempt was made to find out the employees extent of commitment to their jobs. The commitment to job was measured on 4 point scale ranging from stay until retirement to leave as soon as possible. Table shows that only 4.4 per cent of the employees intend to leave the organization as soon as possible. Out of which Chandigarh employees were in majority. 21.7 per cent of respondents feel that if any better opportunity turns up, they will leave the present organization. Only 12.8 per cent of respondents were found in support of the argument that they will leave the organization if an exceptional opportunity turns up. A majority of respondents (61.1 percent) showed accord to the opinion that they will leave the organization only after retirement. 
Table 6: Unit-Wise Analysis of Employee's Propensity to Stay with Job

\begin{tabular}{cccccc}
\hline BBMB Units & $\begin{array}{c}\text { As soon as } \\
\text { Possible }\end{array}$ & $\begin{array}{c}\text { Something } \\
\text { better turns }\end{array}$ & $\begin{array}{c}\text { Exceptional } \\
\text { opportunity }\end{array}$ & $\begin{array}{c}\text { Until } \\
\text { retirement }\end{array}$ & Total \\
\hline Bhakra Nangal & $5(3.3)$ & $36(24)$ & $15(10)$ & $94(62.7)$ & $150(100)$ \\
Talwara & $5(5.9)$ & $22(25.9$ & $13(15.3)$ & $45(52.9)$ & $85(100)$ \\
Sundernagar & $1(1.3) \backslash$ & $6(8.0)$ & $10(13.3)$ & $58(77.3)$ & $75(100)$ \\
Chandigarh & $5(10)$ & $14(28)$ & $8(1.6)$ & $23(46)$ & $50(100)$ \\
Total & $16(4.4)$ & $78(22.17)$ & $46(12.8)$ & $220(61.1)$ & $360(100)$
\end{tabular}

Note: Figure in parenthesis shows percentages.

The table statistics reveals that 10 per cent respondents of the Chandigarh unit showed immediate concern to leave the organization. It is also interesting to note that the Chandigarh (28 percent) Talwara (25.9 percent), Bhakra Nangal (24 percent) employees have expressed that they will leave the organization if something better turns up to them. The organization has to notice the fact and measures should be taken. In overall, the majority of the respondents from all unit analysis trend shows that they will stay in the job until retirement. It shows that majority of respondents of all units showed satisfaction with their job. Thus, it can be concluded that a few of the respondents responded to leave the organization in normal conditions. The employees want to stay with present job means that, they are satisfied with their job. The fact confirms that the more satisfied employees will definitely supports the fact that they will stay until they retire from this job.

Unit-Wise Analysis of Job Performance: The respondents were asked to rate their performance at job on Five Point Likert Scale from poor performance to the outstanding performance rating. The table statistics revealed that out of 360 respondents, no employee have rated his performance as poor. Only 1.9 per cent respondents show their performance below average; 19.4 percent of the respondents exhibit average performance at job. The majority (41.4) of the respondents in the organization show above average performance. Table also exhibits that only 4 per cent of the Bhakra Nangal employees feel their performance as below average. Among average rating results the Chandigarh respondents (34) showed highest share to rate their performance as average. It is also interesting to note that the

Table 7: Unit-Wise Classification of Respondents towards Job Performance Opinion

\begin{tabular}{ccccccc}
\hline \multirow{2}{*}{ BBMB Units } & \multicolumn{4}{c}{ Job Performance Opinions } & Total \\
\cline { 2 - 6 } & Poor & $\begin{array}{c}\text { Below - } \\
\text { Average }\end{array}$ & Average & $\begin{array}{c}\text { Above- } \\
\text { Average }\end{array}$ & $\begin{array}{c}\text { Outstandin } \\
\text { g }\end{array}$ & \\
\hline Bhakra-Nangal & $0(0)$ & $6(4)$ & $27(18)$ & $59(39.3)$ & $58(38.7)$ & $150(100)$ \\
Talwara & $0(0)$ & $0(0)$ & $16(18.8)$ & $28(32.90$ & $41(48.2)$ & $85(1000$ \\
Sundernagar & $0(0)$ & $0(0)$ & $10(13.3)$ & $37(49.3)$ & $28(37.3)$ & $75(100)$ \\
Chandigarh & $0(0)$ & $1(2)$ & $17(34.0)$ & $25(50)$ & $7(14)$ & $50(100)$ \\
Total & $0(0)$ & $7(1.9)$ & $70(19.4)$ & $149(41.4)$ & $134(37.2)$ & $360(100)$ \\
\hline
\end{tabular}

Note: Figure in parenthesis shows percentages.

The above average performance rating was marked in majority by the Chandigarh unit with 50 per cent. Above all, the respondents who rate their performance as outstanding in majority came from Talwara (Beas) unit. The result of the unit-wise job performance confirms the fact of higher Job Satisfaction score of the talwara (Beas) unit. Thus, it can be concluded that the majority of the respondents rate their performance above average. Talwara unit respondents have rated their performance outstanding in majority among the rating of outstanding performance. It can also be concluded that a highly satisfied employees do have the opinion of above average performance or outstanding performance at job.

Unit and Factor-Wise Analysis of Job Satisfaction: A major contention, in the present study is that whether, the different projects or units have any significant difference on overall job satisfaction score and different factors-wise scores. The respondents were arranged according to the units. The means and standard deviations of all dimensions and overall job satisfaction scores were calculated. Dimension-wise analysis is also presented in the table. Organizational factors dimension of job satisfaction inventory (JSI) shows highest mean in Talwara units (23.83). The Sundernagar unit has observed second highest mean (23.28) score for the said factor. The Chandigarh and Talwara unit, mean score were less than the overall 
mean score of organizational factors $(22.62)$. The results of $F$ test (' $F$ ' Value $=7.52$ ) shows significant difference between unit means. Organizational-factor dimension includes the item of organizational policies, wages and salary administration, promotion and advancement, fringe benefits, job safety and security and the work recognition factors. Unit wise means difference among employees on this dimension have significant greater mean score from other units. Furthermore, work-environment factor analysis depicts that the overall mean score (15.45) was above the neutral score (12). The lowest score (14.14) was observed in the case of Chandigarh unit. Talwara unit mean score (16.50) on this factor was observed highest among all units. Talwara-unit mean score on work-environment factors i.e., supervision, Management behavior, physical facilities, and inter-personal relationship factors have significant difference from the remaining organization units taken under study. Moreover, work-itself factors include 6 items of overall Job Satisfaction inventory (21). The overall means score of these factors have observed 24.29. The maximum score was observed in the Sundernagar unit. ' $F$ ' test (15.08) shows significant difference between units' means regarding the work-itself factors. Sundernagar units highest mean score over the work-itself factors i.e., duration of Job, present work satisfaction; autonomy at Job, feeling of responsibility and social status at Job reveals that the employees of this unit. Personal factors has includes 5 items of Job Satisfaction inventory (JS.I). The respondents' satisfaction score on this factor was found 19.58. This score was above the mean standard score (15). The Chandigarh respondents have expressed lowest mean score on this factor. While, the Talwara unit respondents shows highest (20.12) mean score on this factor. The ' $F$ ' ratios (6.77) have found significant difference between personal-factors mean scores of the units. Again the Talwara unit employees have obtained a greater mean score over the personal factor dimension items i.e., challenge at Job, ability utilization, self-esteem at Job and the satisfaction from personal life. This indicates that the Talwara unit employees have shown high satisfaction in comparison to the other three units. Finally, the overall Job satisfaction score was analyzed unit-wise. The overall mean score is observed much higher (81.95) than the mean standard score on the J.S. I $(21$ X $3=63)$. Bhakra-Nangal and Chandigarh units overall Job Satisfaction score was lower than the overall Job Satisfaction score in the Organization. This score was obtained from the summated score of all items response on five point likert scale. The responses were asked from highly satisfied to highly dissatisfied options. The score on extremes was arbitrarily scored from 5 to 1 on the five point likert scale.

However, the highest and lowest score on overall Job Satisfaction were observed in Talwara unit (86.49) and Chandigarh Unit (77.32). While the one way ANOVA technique have been applied to test that whether units employees have any significant difference on Job Satisfactions factors or dimensions score. The observed value of ' $\mathrm{f}$ ' ratios revealed significant difference in each Job Satisfaction dimensions observed mean in units. Thus, it supports to reject the proposed hypothesis (Ho) that there would not have any significant difference on Job Satisfaction dimensions and overall Job Satisfaction. The F. Ratio value (14.57) leads to conclude that the unit-wise overall Job Satisfaction of B.B.M.B employees have significant difference in this organization. Thus, it can be summarized that the Unit-wise analysis of overall and dimension wise inferences leads to conclude that the units have significant place in the determination of attitude towards overall and dimensions specific Job Satisfaction.

Table 8: Unit-Wise Analysis of Job Satisfaction Dimensions

\begin{tabular}{|c|c|c|c|c|c|c|c|c|c|c|c|c|c|}
\hline \multirow{3}{*}{$\begin{array}{c}\text { Job } \\
\text { Satisfaction } \\
\text { Dimensions }\end{array}$} & \multirow{3}{*}{ 華 } & \multicolumn{8}{|c|}{ Units/Projects } & \multirow{2}{*}{\multicolumn{2}{|c|}{$\begin{array}{c}\begin{array}{c}\text { Overall } \\
\text { Score }\end{array} \\
\begin{array}{c}\text { (N = 360) } \\
\text { (BBMB) }\end{array}\end{array}$}} & \multirow{3}{*}{$\begin{array}{c}\text { 'F' } \\
\text { Ratio }\end{array}$} & \multirow{3}{*}{$\begin{array}{c}\text { p- } \\
\text { value }\end{array}$} \\
\hline & & \multicolumn{2}{|c|}{$\begin{array}{l}\text { Bhakra Nangal } \\
\qquad(\mathrm{N}=150)\end{array}$} & \multicolumn{2}{|c|}{$\begin{array}{c}\text { Talwara } \\
(\mathrm{N}=85) \\
\text { (Beas Dam) }\end{array}$} & \multicolumn{2}{|c|}{$\begin{array}{c}\text { Sundernagar } \\
\text { (N = 75) } \\
\text { (BSL) }\end{array}$} & \multicolumn{2}{|c|}{$\begin{array}{c}\text { Chandigarh } \\
(\mathrm{N}=50) \\
\text { (Secretariat) }\end{array}$} & & & & \\
\hline & & $(\bar{X})$ & $(\sigma)$ & $(X)$ & $(\sigma)$ & $(\bar{X})$ & $(\sigma)$ & $(\bar{X})$ & $(\sigma)$ & $(X)$ & $(\sigma)$ & & \\
\hline $\begin{array}{l}\text { Organizational } \\
\text { Factors } \\
\text { Work- }\end{array}$ & 6 & 21.84 & 3.69 & 23.85 & 3.86 & 23.28 & 3.69 & 21.74 & 3.19 & 22.62 & 3.77 & 7.525 & $<0.01$ \\
\hline $\begin{array}{l}\text { Environmental } \\
\text { Factors }\end{array}$ & 4 & 14.8 & 2.52 & 16.50 & 2.67 & 16.26 & 2.26 & 14.14 & 2.42 & 15.45 & 2.63 & 14.89 & $<0.01$ \\
\hline $\begin{array}{l}\text { Work- Itself } \\
\text { Factors }\end{array}$ & 6 & 23.40 & 3.59 & 25.55 & 3.15 & 25.62 & 3.07 & 22.84 & 3.29 & 24.29 & 3.49 & 15.08 & $<0.01$ \\
\hline Personal factors & 5 & 19.08 & 3.21 & 20.57 & 3.11 & 20.12 & 2.89 & 18.60 & 2.79 & 19.58 & 3.14 & 6.778 & $<0.01$ \\
\hline $\begin{array}{l}\text { Overall Job } \\
\text { Satisfaction }\end{array}$ & 21 & 79.21 & 10.36 & 86.49 & 11.30 & 85.40 & 9.97 & 77.32 & 10.46 & 81.95 & 11.11 & 14.57 & $<0.01$ \\
\hline
\end{tabular}

\section{Conclusion and Recommendations}

A large chunk of respondents in the sample belongs to Bhakra Nangal unit followed by Talwara unit 23.61 percent. Job Satisfaction means were 79.21, 86.49, 85.40 and 77.32 and standard deviation of 10.36, 
11.30, 9.97, and 10.46 were observed respectively for Bhakra Nangal, Talwara, Sundernagar and Chandigarh secretariat respectively. So far mean difference according to units is concerned on job satisfaction; the null hypothesis may be rejected in this regard. Thus, it can be concluded that the Talwara unit mean among units was not variated due to chance but is placed at a large extent by significant reasons. As regard the job satisfaction rating is concerned, only 1.1 percent respondents found dissatisfied in overall with job. 41.1 percent employees have rated job satisfaction as highly satisfied. A majority, 43.3 percent of respondent rates job satisfaction as quite satisfied. Unit-wise analysis depicts that Sundernagar unit employees emerge as highest percentage followed by Talwara Unit among highly satisfied. Talwara and Sundernagar units' respondents have known to have no dis-satisfied employee at job. Analyses on commitment opinion of employees to stay at job have revealed that only 4.4 percent employees intend to leave the organization as soon as possible. Whereas, 61.1 percent respondents tend to stay at present job until retirement. As far as the unit-wise analysis is concerned, in this regard 10 percent respondents of Chandigarh want to leave the organization as soon as possible. Chandigarh respondents do not feel happy with the organization and only 46 percent of them want to stay until retirement. Sundernagar respondents show maximum percentage among the stay until retirement alternative on the scale.

Regarding the job-performance self-evaluation, no employee has found to rate his performance as poor. Only 1.9 percent respondents viewed as below average performance opinion. The majority respondents (41.4 percent) known to have above average performance raters. The unit-wise comparison depicts that among average performance evaluation; the Chandigarh employees are dominant followed by those in Talwara unit. Whereas, the outstanding performance evaluation resulted that a majority of Talwara unit respondents assessed their performance as outstanding. Finally, the majority respondents rate their performance above average. Unit-wise and overall job satisfaction dimensions comparison have revealed interesting results. The dimension-wise highest mean score have been observed for organizational factors dimension by Sundernagar $\overline{\mathrm{x}}=23.28$, work-environment factor by Talwara, $\bar{X}=16.50$, work-itself factors dimension by Sundernagar, $\bar{x}=25.62$, and the personal-factors dimension by Talwara, $\bar{x}=86.49$. The lowest mean on overall job satisfaction among units was viewed for Chandigarh secretariat by $\overline{\mathrm{x}}=77.32$. However, the variance analysis derived significant means difference of higher mean on all job satisfaction dimensions along with overall job satisfaction in the organization. Hence, it can be revealed that there is wide difference in the observed means on overall and dimension wise Job satisfaction from lower score of BBMB units.

Recommendations of the study: Despite being the above mean score observation for four units of BBMB on job satisfaction, the significant mean difference finding highlights to focus on the units which had observed lower mean scores among units. The findings on employee's commitment to stay at job strongly emphasize that only 4.4 percent employees want to leave this organization as soon as possible. But the major concern is that if something better turns in career they will leave organization has been stated by about 22.17 percent employees. It is suggested that the employees dissatisfaction and the reasons for leaving the organization should be analyzed and required to announce better opportunities in the organization. Unit-wise analysis of overall and job satisfaction dimension has revealed that there is significant difference of mean score of units. Thus, it is suggested that the lower mean score units on job satisfaction dimensions and overall job satisfaction should have to strengthen the overall or specific facets on which the mean was lower. Chandigarh unit respondent's shows lowest mean score on all dimensions therefore this particular unit has to resolve the lower mean score by appropriate actions.

Limitations of the study: To complete the present research work no stone has been left unturned in view to make it best possible work. Non-probability method of sampling, stringency of time, resources, and the incomplete and non-responses of certain items may lose the tools authenticity. The concept of job satisfaction is not entirely specific even though efforts have been made to use it in the present study to meet our purpose. The rating method of job satisfaction rating is not a full proof method. Despite of these limitations all precautions have been made in order to make its impact negligible on the research results and findings.

Area for the further research: A number of studies including the present one have been conducted on job satisfaction in the public and private sector. The present study has been conducted for the realization of certain objectives. Though, every attempt has been made to make the study comprehensive besides, certain areas have still remained unexplored. Job satisfaction is a culture specific exercise. Its form and 
contrast very with prevailing socio-economic, cultural and technological milieu of a country. There are still certain areas left on which further research should be carry out:

- No discovery is final verdict in a particular area of research.

- A replication of the same study can be carried out having a wider research area.

- Further, the researches have to apply a standard tool for data collection.

\section{References}

Chaudhry, S. (1989). Occupational Level and Job Satisfaction. Indian Journal of Applied Psychology, 26 (2), 1-5.

Dhillon, P. K. (1989). Relationship between Organizational Stress and Job Satisfaction. Indian Journal of Current Psychological Research, 4(1), 42-47.

Herzberg, F., Mausner, B., Peterson, R.O. \& Capell, D.F. (1957). Job Attitude: Review of Research and Opinion, Psychological Services of Pittisburgh, Pittisburgh 4(11), 44-55.

Likert, R. (1967). The Human Organization (New York): Mcgrawhill.

Locke, E. A., (1969). What is Job Satisfaction? Organizational Behaviour and Human Performance. 2, 309336.

Locke, E. A. (1970). Job Satisfaction and Job Performance: A Theoretical Analysis. Organizational Behaviour and Human Performance, 5, 484-500.

Maslow, A.H. (1954). Motivation and Personality. N.Y., Harper and Row.

Mohammad, M. H. (2000). Job satisfaction of Commercial bank employees in Bank employees in Bangladesh: A Comparative study of private and Public sectors. Indian Journal of Industrial Relations, 35(4), 397-361.

Nunnally, J. C. \& Bernstein, I. H. (1994). Psychometric Theory (3rd Ed.). New York: McGraw-Hill.

Sathyadas, D. (1979). A Comparative Study of Type Job Satisfaction and Temperament of Teachers and Clerks, Indian of Applied Psychology, 16(2), 89-94.

Spector, P. (1997). Job satisfaction: Application, assessment, causes and consequences. Thousand Oaks, CA: Sage. 